\title{
Liquid MALDI MS analysis of complex peptide and proteome samples
}

Article

Accepted Version

Wiangnon, K. and Cramer, R. (2016) Liquid MALDI MS analysis of complex peptide and proteome samples. Journal of Proteome Research, 15 (9). pp. 2998-3008. ISSN 1535-3907 doi: https://doi.org/10.1021/acs.jproteome.6b00148 Available at https://centaur.reading.ac.uk/66159/

It is advisable to refer to the publisher's version if you intend to cite from the work. See Guidance on citing.

To link to this article DOI: http://dx.doi.org/10.1021/acs.jproteome.6b00148

Publisher: American Chemical Society

All outputs in CentAUR are protected by Intellectual Property Rights law, including copyright law. Copyright and IPR is retained by the creators or other copyright holders. Terms and conditions for use of this material are defined in the End User Agreement.

\section{www.reading.ac.uk/centaur}

\section{CentAUR}

Central Archive at the University of Reading

Reading's research outputs online 


\title{
Liquid MALDI MS analysis of complex peptide and proteome samples
}

\author{
Kanjana Wiangnon and Rainer Cramer* \\ Department of Chemistry, University of Reading, Whiteknights, Reading, RG6 6AD, UK
}

*Corresponding author:

Prof. Rainer Cramer

Department of Chemistry

University of Reading

Whiteknights

Reading RG6 6AD

UK

Phone: 0044-118-378-4550

Email: $\underline{\text { r.k.cramer@reading.ac.uk }}$

Keywords: liquid support matrix, liquid MALDI, MALDI-TOF, QTOF, mass spectrometry, LCMALDI, automation, MALDI-PSD, MALDI-CID, MALDI MS/MS 


\begin{abstract}
Matrix-assisted laser desorption/ionization (MALDI) time-of-flight (TOF) mass spectrometry (MS) is well-known to be a powerful technique for the analysis of biological samples. By using glycerol-based liquid support matrices (LSMs) instead of conventional MALDI matrices the power of this technique can be extended further. In this study, we exploited LSMs for the identification of complex samples, i.e. the Lactobacillus proteome and a bovine serum albumin (BSA) digest. Liquid and solid MALDI samples were manually and robotically prepared by coupling a nanoflow high performance liquid chromatography (nanoHPLC) system to an automated MALDI sample spotting device. MS and MS/MS data were successfully acquired at the femtomole level using $\mathrm{TOF} / \mathrm{TOF}$ as well as Q-TOF instrumentation and used for protein identification searching sequence databases. For the BSA digest analysis, liquid MALDI samples resulted in peptide mass fingerprints which led to a higher confidence in protein identification compared to solid (crystalline) MALDI samples. However, post-source decay (PSD) MS/MS analysis of both the proteome of Lactobacillus plantarum WCFS1 cells and BSA digest showed that further optimization of the formation and detection of peptide fragment ions is still needed for liquid MALDI samples as the MS/MS ion search score was lower than for the solid MALDI samples, reflecting the poorer quality of the liquid MALDI-PSD spectra, which can be attributed to the differences in PSD parameters and their optimization that is currently achievable.
\end{abstract}




\section{Introduction}

Mass spectrometry (MS) is a key tool in proteomic research, enabling the identification, characterization and quantification of peptides and proteins. The most common soft ionization methods in MS are matrix-assisted laser desorption/ionization (MALDI) and electrospray ionization (ESI). The benefits of MALDI as an ionization technique include high sensitivity (low femtomole range or lower) and high tolerance to contaminants such as salts, buffers and other impurities. The sample preparation is simple and requires only small amounts of analyte. In addition, there is also the potential of recovering residual amounts of analyte. The versatility of MALDI MS has been demonstrated in many applications. ${ }^{1-3}$

In general, matrices and solvents for MALDI sample preparations are carefully chosen for optimal analyte detection. Matrices such as 2,5-dihydroxybenzoic acid (DHB) and $\alpha$-cyano-4hydroxycinnamic acid (CHCA) have been widely employed for solid (crystalline) MALDI samples. However, such solid MALDI samples are not well suited for quantitative measurements and/or automated data acquisition because of heterogeneous crystallization, resulting in highly variable ion yields and desorption/ionization characteristics. As an alternative to the traditional matrices and solid MALDI samples, liquid support matrices (LSMs) provide increased shot-toshot reproducibility at low sample consumption, leading to prolonged and stable ion signals. ${ }^{4-7}$ Liquid matrices are often based on the dissolution of an acidic solid matrix with a basic organic reagent such as 3-aminoquinoline (3-AQ) as a solubilizing assistant. ${ }^{4-12}$ The use of a (viscous) liquid with low-volatility such as glycerol in conjunction with this acid/base system supports the

sample to remain liquid, even under vacuum conditions. ${ }^{4-7}$ In contrast to solid MALDI samples, liquid MALDI samples give greater homogeneity with a more constant spot morphology after 
irradiation due to the self-healing and renewing properties of the liquid samples. As the spot remains liquid under vacuum, a prolonged period of ion generation and detection is also possible in (high-)vacuum MALDI instruments such as axial TOF and Q-TOF instruments. Thus, this approach facilitates the application of MALDI MS for automation and quantification using commercial instrumentation. ${ }^{5-7}$

In MS-based studies of complex proteomes, MS is often coupled to liquid chromatography (LC) separation either in an on-line or off-line format. LC coupling to MALDI is typically carried out off-line with the MALDI matrix and LC eluent fractions being mixed and spotted onto the MALDI target. A few studies have attempted to analyze complex proteomic samples with this approach and achieved protein identification at the low-femtomole level using proteolytic digests. ${ }^{13-15}$

To date, most proteomics research has focused on using on-line LC interfaced with ESI MS. However, there are some notable advantages in interfacing LC with MALDI rather than ESI for the analysis of a complex peptidic digest mixture. With on-line LC-ESI MS, the time interval is often too short for the acquisition of fragment ion spectra of all the sample components. This time constraint does not apply to off-line LC-MALDI MS. The sample can be stored on the MALDI target plate for at least several days without analyte degradation. Another potential benefit is the detection of mainly singly charged ions, whereas ions are typically detected as multiply charged species in ESI MS. This difference to ESI MS enables easy interpretation of the mass spectra. However, due to the differences between MALDI and ESI, they each have specific advantages over the other. Therefore, combining the data from both LC-ESI MS/MS and LCMALDI MS/MS approaches have improved the number of proteins identified and the protein coverage of complex protein digest mixtures. ${ }^{16-18}$ 
The aim of the presented research has been the optimization of liquid MALDI sample preparation for the identification of complex proteomic samples using bottom-up proteomics as the analytical strategy with bovine serum albumin (BSA) and Lactobacillus proteome digests as analytes. As with ESI-based proteomics the analysis of a complex protein sample involved the use of a nanoflow HPLC system for the separation of the digest peptides. The HPLC system was coupled to an automated sample spotting robot that simultaneously co-spots liquid MALDI matrix aliquots with HPLC fractions. The ability to use nanoHPLC-MALDI MS and MS/MS for the identification of a BSA digest resulted in its successful identification with high protein sequence coverage. In the initial experiments badly resolved and unidentifiable high-intensity peaks appeared in post-source decay (PSD) MS/MS spectra acquired on an axial TOF/TOF instrument. These peaks and their impact on protein identification were further investigated in this study. 


\section{Experimental Section}

\subsection{Materials}

Peptide calibration standard II (cat.no. 222570) and CHCA were purchased from Bruker Daltonics (Coventry, UK). BSA, Glu-1-fibrinopeptide B (Glu-Fib), 3-aminoquinoline (3-AQ), ammonium phosphate (AP), ammonium citrate (AC), ammonium bicarbonate (ABC), glycerol, dithiothreitol (DTT), and iodoacetamide (IAA) were obtained from Sigma-Aldrich (Poole, UK). Sequencing-grade modified trypsin was purchased from Promega (Southampton, UK). Trifluoroacetic acid (TFA) was from Thermo Scientific (Rockford, IL, USA). The organic solvents used were also obtained from Sigma-Aldrich while the HPLC gradient-grade water came from Thermo Fisher Scientific (Loughborough, UK). All chemicals and solvents were used without further purification.

L. plantarum WCFS 1 was originally isolated from human saliva (National Collection of Industrial and Marine Bacteria, Aberdeen, UK). It was kindly donated by Mr. Pornpoj Srisukchayakul (Food and Nutritional Sciences, University of Reading, Reading, UK).

\subsection{Analyte Preparations}

A tryptic digest of BSA was prepared by dissolving $10 \mu \mathrm{g}$ of BSA in $50 \mathrm{mM} \mathrm{ABC}$. DTT was added to achieve a final concentration of $10 \mathrm{mM}$ and the mixture was incubated at $45^{\circ} \mathrm{C}$ for 45 min to cleave disulphide bridges. Subsequently, the cleaved disulphide bridges were alkylated by reaction with $30 \mathrm{mM}$ IAA in the dark for $45 \mathrm{~min}$. The excess IAA was quenched by the addition of DTT for 45 min. Trypsin was then added to the sample in a ratio of 1:50 (w/w) (Trypsin:BSA) and the sample was left overnight at $37^{\circ} \mathrm{C}$. The digestion was stopped by adding TFA to bring the $\mathrm{pH}$ of the mixture to $<4$. The BSA-digest solution was then dried by a speed vacuum 
concentrator for $2 \mathrm{~h}$. The dried BSA-digest pellet was suspended in 0.1\% TFA prior to LCMS/MS analysis.

Lactobacillus plantarum WCFS1 was cultured at $37^{\circ} \mathrm{C}$ for $24 \mathrm{~h}$ with shaking at $180 \mathrm{rpm}$. After $16 \mathrm{~h}$, cell samples were harvested at the cells' stationary phase by centrifugation at $4^{\circ} \mathrm{C}$ for 10 $\min$ at 3,000 rpm. The supernatant was discarded, and the remaining sample was washed twice with phosphate buffered saline (PBS) at $\mathrm{pH}$ 7.4. Cell walls were mechanically broken by vibrating/milling with microbeads at high speed using a Minibeat beater $(3 \times 1 \mathrm{~min})$. The resulting protein solution was aliquoted and the aliquots were subsequently digested with trypsin using a similar protocol as was used for BSA. Finally, the digests were cleaned and concentrated by solid phase extraction (SPE) using $1 \mathrm{cc}$ Sep-Pak $\mathrm{C}_{18}$ Vac cartridges with $50 \mathrm{mg}$ sorbent per cartridge and a particle size of 55-105 $\mu \mathrm{m}$ (Waters). The eluted samples were concentrated using a speed vacuum concentrator for $1 \mathrm{~h}$ until completely dry. The pellets were subsequently reconstituted with $0.1 \%$ of TFA prior to performing nanoLC-MALDI MS/MS.

The peptide (calibration) standard II solutions were prepared according to the manufacturer's instructions, aliquoted and kept at $-80^{\circ} \mathrm{C}$ until analysis.

Glu-Fib analyte solutions were prepared at a concentration of $10 \mathrm{pmol} / \mu \mathrm{l}$ in water, and also aliquoted and kept at $-80^{\circ} \mathrm{C}$ until analysis.

\subsection{MALDI Sample Preparations}

Solid MALDI samples

For axial TOF/TOF measurements, the matrix CHCA was prepared at $1 \mathrm{mg} / \mathrm{ml}$ in a $1 \mathrm{mM}$ AP/ $0.1 \%$-TFA solution of $85 \%$ acetonitrile and $15 \%$ water. The matrix solution was mixed with 
the analyte solution in a ratio of $1: 1(\mathrm{v} / \mathrm{v})$, and $1 \mu \mathrm{l}$ of the matrix-analyte solution was spotted on a 600- $\mu \mathrm{m}$ AnchorChip target plate (Bruker Daltonics) and allowed to dry for $45 \mathrm{~min}$ at ambient temperature. For calibration samples, the same preparation was applied using the peptide calibration standard II solution instead of the analyte solution mixed in a ratio of 200:1 (v:v; matrix:peptide solution).

For Q-TOF measurements, the CHCA solution was prepared at $3 \mathrm{mg} / \mathrm{ml}$ in a $0.1 \%$-TFA solution of $\sim 50 \%$ acetonitrile and $\sim 50 \%$ methanol. A volume of $0.5 \mu \mathrm{l}$ of matrix solution was spotted on a commercial steel MALDI target and an additional $0.5 \mu \mathrm{l}$ of analyte solution was applied on top. The analyte-matrix mixture was allowed to dry under ambient conditions for $20 \mathrm{~min}$. The Q-TOF instrument was calibrated using the fragmentation spectrum of Glu-Fib.

Automated solid MALDI sample preparation of nanoHPLC-separated analyte fractions is described in section 2.4 .

\section{Liquid MALDI samples using LSM}

For the (glycerol-based) LSM, CHCA and 3-AQ were dissolved in 50\% methanol/50\% $20 \mathrm{mM}$ ammonium phosphate (solution $\mathrm{X}$ ) and glycerol in the ratio of 1:3:5:5 $(\mathrm{w}[\mathrm{mg}]: \mathrm{w}[\mathrm{mg}]: \mathrm{v}[\mu \mathrm{l}]: \mathrm{v}[\mu \mathrm{l}])$. The mixture was vortexed and sonicated for 15 min until all solutes were dissolved and a clear yellow single-phase solution was obtained. This stock matrix solution was stored at $4{ }^{\circ} \mathrm{C}$ for up to one week and further diluted 20 -fold in solution $\mathrm{X}$ prior to analysis.

For axial TOF/TOF measurements, the diluted matrix solution was mixed with the analyte solution in a ratio of $1: 1(\mathrm{v} / \mathrm{v})$, and $1 \mu \mathrm{l}$ of this matrix-analyte solution was spotted and dried in the same manner as for the solid MALDI samples. For calibration samples, the same preparation 
was applied using the peptide calibration standard II solution instead of the analyte solution mixed in a ratio of 200:1 (v:v; matrix:peptide solution).

For Q-TOF measurements, $0.5 \mu 1$ of the diluted liquid matrix was deposited on a steel MALDI target plate and a $0.5-\mu 1$ aliquot of the analyte solution was spotted on top. The analyte-matrix mixture was left to dry under ambient conditions for $20 \mathrm{~min}$. The Q-TOF instrument was calibrated using the fragmentation spectrum of Glu-Fib.

Automated liquid MALDI sample preparation of nanoHPLC separated analyte fractions is described in section 2.4 .

\subsection{NanoHPLC and Automated MALDI Sample Spotting}

An Ultimate nanoHPLC system (Dionex, Hemel Hempstead, UK) was coupled directly to a PROTEINEER fc liquid handler (Bruker Daltonics). These systems were both controlled by Hystar software (Bruker Daltonics). The nanoHPLC system had two pumps: the loading pump with a Switchos system that switched between the trapping column and the analytical column and a nanoflow LC pump (Model Ultimate, LC Packings) with a NAN-75 cartridge for splitting the flow rate from $187 \mu 1 / \mathrm{min}$ to $300 \mathrm{nl} / \mathrm{min}$. The trapping column used was an Acclaim PepMap $300 \mu \mathrm{m}$ i.d. x $1 \mathrm{~cm}$ column ( $3-\mu \mathrm{m}$ C18 particles). Two analytical columns were used. For BSA digests, this was an Acclaim PepMap $75 \mu \mathrm{m}$ i.d. x $15 \mathrm{~cm}$ column (3- $\mu \mathrm{m} \mathrm{C}_{18}$ particles), and for bacterial protein digests a similar column but $25 \mathrm{~cm}$ long was found to be more appropriate. An autosampler was used for the injection and loading of the sample onto the trap column. The loading solvent was the mobile phase solution A, comprising of $2 \%$ acetonitrile/ $0.01 \%$ TFA. A volume of $1 \mu \mathrm{l}$ of the analyte solution containing 500 fmol of tryptic BSA digest or $1 \mu \mathrm{g}$ of bacterial protein digest was injected at a flow rate of $20 \mu \mathrm{l} / \mathrm{min}$ onto the trap column. After $5 \mathrm{~min}$ 
of loading, the valve was switched to an in-line position with the analytical column at a flow rate of $300 \mathrm{nl} / \mathrm{min}$. The mobile phase used for the HPLC run was made up of solution A (2\% acetonitrile/0.01\% TFA) and solution B (90\% acetonitrile/0.01\% TFA). A gradient of increasing percentage of solution B was used, going from $10 \%$ to $95 \%$ in 35 min for the BSA digest and $3 \%$ to $55 \%$ in $125 \mathrm{~min}$ for the bacterial protein digest. The UV detector was set to measure at 214 $\mathrm{nm}$. The 3-nl UV flow cell was connected to the MALDI spotter by fused silica tubing (20 $\mu \mathrm{m}$ i.d., $360 \mu \mathrm{m}$ o.d., $100 \mathrm{~cm}$ ). For BSA digest analyses, eluent fractions were spotted every $30 \mathrm{~s}$ onto the MALDI target plate within the time interval of 20-50 min, when peptides eluted, while for bacterial protein digest analyses the spotting duration was reduced to $15 \mathrm{~s}$ and fractions were taken from 20-120 min. The matrix solution was deposited on the target by a probe connected to a syringe pump. Matrix solutions for solid MALDI and liquid MALDI samples were the same as described in section 2.3. The volume of the matrix solution added was defined by the flow rate (in continuous flow mode): $1.7 \mu 1 / \mathrm{min}$ for solid MALDI samples and 3-4 $\mu 1 / \mathrm{min}$ for liquid MALDI samples. Alternatively, in discontinuous flow mode, deposition of the matrix solution was $0.5-1 \mu 1$ per spot. Prior to the analyte fractionation and matrix solution deposition, the $x-y-z$ coordinates of the 600- $\mu \mathrm{m}$ AnchorChip target were taught to ensure that the tip of the spotting capillary closely approached the surface of the MALDI target without touching it.

\subsection{Data Acquisition, Processing and Analysis}

TOF/TOF data acquisition, processing and analysis

TOF/TOF measurements were performed on an Ultraflex instrument (Bruker Daltonics) employing positive ion and reflectron mode. The instrument was calibrated using a standard peptide mixture described earlier. MS data were collected with the ion source 1 set to $25.00 \mathrm{kV}$ 
and ion source 2 set to $21.75 \mathrm{kV}$. The lens voltage was set to $8.50 \mathrm{kV}$ and reflector 1 was set to $26.30 \mathrm{kV}$ with reflector 2 at $13.75 \mathrm{kV}$. Matrix suppression below $500 \mathrm{Da}$ was used. The PSD MS/MS measurements were performed using LIFT technology.

Analysis of the fractionated samples was performed automatically using the AutoXecute function in FlexControl (Bruker Daltonics). For liquid MALDI samples the data was collected from the centre of the spot without changing the desorption position, with a laser repetition rate of $25 \mathrm{~Hz}$. The spectra of 500 laser shots were summed. For the crystalline MALDI samples the data was collected from multiple 'sweet spot' positions with a laser repetition rate of $50 \mathrm{~Hz}$. The spectra of 100 laser shots were acquired from each position, and 5 of these acquisitions using a total of 500 laser shots were summed to give the final spectra.

After MS data acquisition, MS spectral peaks were selected using FlexAnalysis software version 3.0 (Bruker Daltonics). Peak selection was performed automatically using the SNAP (Sophisticated Numerical Annotation Procedure) algorithm with a peak signal-to-noise $(\mathrm{S} / \mathrm{N})$ ratio of $\geq 6$, peak resolution of $>500$ and a limit of 300 peaks selected. The WARP-LC software (version 1.1; Bruker Daltonics) was used to establish a peak list of an entire LC experiment after peak selection. WARP-LC was then used for the automatic selection of peptide signals and their subsequent MS/MS analysis. Automated MS/MS data acquisition was performed by using the LIFT technology of the Ultraflex TOF/TOF instrument. For this, LIFT spectra were obtained from the accumulation of 300 parent ion spectra and 500 single-shot fragment ion spectra for each selected parent ion. A maximum of 10 parent ion signals per fraction were analysed starting preferentially in the range $\mathrm{m} / \mathrm{z} 800-3500$. The LIFT fragment ion peaks were picked using FlexAnalysis after baseline subtraction (median with a 0.8 flatness) and smoothing (SavitzkyGolay; 4 cycles with a width of $\mathrm{m} / \mathrm{z}$ 0.15). Peaks were selected up to a maximum of 200 with a 
peak S/N ratio of $\geq 3$ using the centroid algorithm. MS and MS/MS spectra were sent by WARPLC to the BioTools software version 3.0 (Bruker Daltonics) as combined peak lists for database searching (see section 2.6).

\section{Q-TOF data acquisition, processing and analysis}

Q-TOF measurements were performed on a MALDI Q-TOF Premier mass spectrometer (Waters Corporation, Wilmslow, UK) in positive ion $\mathrm{V}$ mode using a laser emitting at $337 \mathrm{~nm}$ with a repetition rate of $20 \mathrm{~Hz}$. The spectra were collected with cell entrance at $1.5 \mathrm{~V}$, cell exit at -10.3 $\mathrm{V}$, sample plate at $0 \mathrm{~V}$, extraction at $9.0 \mathrm{~V}$, hexapole at $9.9 \mathrm{~V}$, aperture 0 at $3.3 \mathrm{~V}$, and ion guide at $1.5 \mathrm{~V}$. The detector was operated at a voltage of $1800 \mathrm{~V}$.

Q-TOF MS data acquisition resulted from data accumulation of MS scans over 1 min at a scan rate of 1 scan per second. For the solid matrix, the MALDI mass spectra were acquired with the laser irradiation moving in a spiral pattern over the MALDI sample using a step rate of $2 \mathrm{~Hz}$ and a step width of $3.75 \mu \mathrm{m}$. For the liquid matrix, the laser beam was fixed in the centre of the droplet without any movement. The collision energy voltage was set to $4.9 \mathrm{~V}$ and laser pulse energies were optimized to give the highest signal intensity. MassLynx version 4.1 software was used to process the mass spectra. A spectrum was created by summing up the intensities of the total ion chromatograms (TIC) over one minute. The baseline was subtracted and the S/N ratio was calculated.

For MS/MS data acquisition, collision-induced dissociation (CID) was performed with the collision energy voltage settings in the range of 65-80 V. CID fragment ions were collected with a scan rate of $1 \mathrm{~s}$ and an inter-scan delay of $0.02 \mathrm{~s}$. The mass window for transmission of precursor ions was set to 4.7 for low mass resolution and 15.0 for high mass resolution. The mass 
spectra were processed using the Savitzky-Golay smoothing method for a 3 channel window width with 2 iterations while baseline subtraction was done with a polynomial order of 15 and a tolerance of 0.01 .

\subsection{Database Searching}

For BSA analysis, MS and MS/MS peak lists were automatically searched against the Swiss-Prot protein database (version 57.60) using Mascot Server 2.4.1 (Matrix Science, London, UK). For L. plantarum, the MS/MS data was searched against the in-house database of Lactobacillus plantarum WCFS1, containing 3088 protein entries (934,303 residues), which was downloaded on March 31, 2014 from the HAMAP (High-quality Automated and Manual Annotation of microbial Proteomes) database repository website (http://hamap.expasy.org/proteomes/LACPL.html). Peptide mass fingerprinting (PMF) was performed with a mass tolerance of $100 \mathrm{ppm}$, allowing for up to 1 missed cleavage, with a fixed modification of cysteine carbamidomethylation and variable modifications of acetylation at the $N$-terminus and methionine oxidation. MS/MS ions searching was performed with the peptide mass tolerance set to $100 \mathrm{ppm}$ and the MS/MS ion tolerance to $0.7 \mathrm{Da}$. The modifications of fixed carbamidomethylation of cysteines and variable oxidation of methionines were selected. A maximum of 1 missed cleavage was allowed. 


\section{Results and Discussion}

Glycerol-based liquid support matrices (LSMs) have been successfully used as MALDI matrices for peptide and protein analysis, with the benefit of high reproducibility due to the greater homogeneity and prolonged ion signal. This advantage facilitates the identification of proteins by peptide mass mapping using automated sample preparation and data acquisition. ${ }^{6}$ A recent study even used (glycerol-based) LSMs for producing multiply charged peptide and protein ions using an AP ion source. ${ }^{19}$

This study describes a novel approach using liquid MALDI for the analysis of complex protein digests with the automated step of nanoHPLC and MALDI sample spotting being off-line from the MALDI-TOF MS(/MS) analysis. Several LC-MALDI MS approaches have been proposed using solid MALDI samples but there are no reports where liquid (LSM) matrices have been used with LC-MALDI. Zenobi and co-workers have however demonstrated the use of an ionic liquid as the matrix for automated co-deposition with the analyte, using a self-built device, though not in the context of coupling LC and MALDI MS, e.g. for the analysis of complex peptide mixtures. $^{15}$

For this work, the performance of both liquid and solid MALDI sample preparations were tested using the workflow described. While the preparation of the liquid matrix solution requires the addition of a couple of more components (glycerol and base), these are not costly and the additional time needed for the preparation of the liquid matrix stock solution is negligible. As homogeneity is a key aspect of liquid MALDI, sample spots were viewed under a microscope after deposition by the automated spotting device. It was observed that these spots were still in the liquid form even when placed under vacuum in the mass spectrometer, whereas equivalent 
spots made using the solid matrix CHCA appeared as fully dried small crystals after evaporation of the volatile solvent (Figure 1). Mascot search results of the peptide mass fingerprints using these two MALDI sample preparations are compared in Table 1. The total number of selected peaks were $153 \pm 66$ and $172 \pm 74$ for the liquid and solid MALDI samples, respectively. For the liquid MALDI analysis, the average sequence coverage and Mascot score for the BSA digest were $65 \pm 3 \%$ and $258 \pm 11$, respectively, while the same experiment conducted with the solid MALDI sample gave $60 \pm 3 \%$ and $207 \pm 20$, respectively. One of the keys to successful PMF with high scores is the prevention of unwanted clusters and adducts of the matrix compounds as discussed in a previous report. ${ }^{6}$ The lower number of selected peaks obtained using the liquid sample preparation is in agreement with the observation that this liquid MALDI sample preparation can reduce salt adduct and matrix cluster ion signals. ${ }^{6,20}$ Some of these beneficial effects can be attributed to the presence of ammonium phosphate in the liquid MALDI sample. ${ }^{21-26}$ Similarly, the addition of optimal amounts of basic organic compounds to the matrix acid has the effect of decreasing chemical noise, alkali adducts and matrix clusters, further increasing sensitivity. ${ }^{5,6,27,28}$

In Table 1, intensity coverage, a parameter calculated by the software Biotools, represents the sum of the intensities of the matched peaks divided by the sum of the intensities of the peaks that have been selected (multiplied by 100). For the liquid MALDI samples, intensity coverage was $52 \pm 7 \%$, compared to $42 \pm 5 \%$ for the solid MALDI samples. Some of this difference in intensity coverage could be due to the disparity in homogeneity of the samples. For the solid samples, laser shots were taken at random positions. The non-homogeneous distribution of analyte within the crystals easily leads to a reduction in the overall $\mathrm{S} / \mathrm{N}$ as many laser shots typically result in spectra with little or no analyte ion signal, even if the operator (or automated acquisition) is well 
experienced in searching analyte-containing 'sweet spots'. In contrast there is no requirement to search for a 'sweet spot' with the liquid samples due to their homogenous and self-healing properties. Therefore, higher peptide ion signal can be obtained from a single laser position with a persistent analyte ion signal that fluctuates very little from shot to shot.

For MS/MS analysis of a BSA digest, Table 2 presents the database search results for both MALDI sample preparations. The number of matched peptides was the same $(25 \pm 5)$ for both sample preparations, while the protein sequence coverage was higher for the liquid MALDI samples $(50 \pm 8 \%)$ than for the solid MALDI samples $(47 \pm 9 \%)$. However, liquid MALDI gave a poorer Mascot score $(965 \pm 320)$ than solid MALDI $(1299 \pm 244)$. In general, a higher peptide match score was obtained when using solid MALDI (i.e. for 15 out of the 20 peptide ions that were matched in both cases). These results reflect the poorer b- and y-ion assignment in liquid MALDI. A lower mass accuracy is partially the reason for obtaining lower Mascot scores in liquid MALDI. For example, the solid MALDI PSD MS/MS spectrum of the peptide ion at $\mathrm{m} / \mathrm{z}$ 1907.9 led to a BSA peptide match, whereas the respective liquid MALDI spectrum could not be successfully matched because the measured fragment ion masses were outside the mass tolerance window of $\pm 0.7 \mathrm{Da}$, although fragment ion signal intensities were greater (Figure 2). One possible explanation for this low fragment ion mass accuracy lies with the calibration of the LIFT. The LIFT is normally calibrated during the annual preventative maintenance visit by the service engineer using crystalline MALDI samples only and is therefore most likely inadequate for liquid MALDI with its generally thicker sample and different instrument parameter settings and calibration.

Some of the BSA peptides identified using liquid MALDI, for example, m/z 927.4, showed more intense ion signals and achieved a higher ion score with PSD than using solid MALDI (Figure 
3). A comparison was made of all the peptides observed using three replicate analyses with each matrix, but only where the peptide ion was found in more than one replicate were the files selected and data combined. This comparison revealed that seven ions below m/z 1200 were detected when using liquid MALDI as opposed to only three peptide ions found for solid MALDI (see Table 3). There were 20 peptides present in both data sets. Five peptides were exclusively found in solid MALDI, while eight peptides were found only in liquid MALDI (Table 3). The peptides exclusively found using liquid MALDI were all detected below $\mathrm{m} / \mathrm{z}$ 1600 while all apart from one of the peptide ions exclusively obtained with solid MALDI were in the range above this $\mathrm{m} / \mathrm{z}$ value. These results demonstrate the effectiveness of liquid MALDI in the detection of peptide ions in the low mass range, as has been shown previously. ${ }^{6}$ Again, a possible reason for this is the reduction in matrix interference seen in the low mass region.

Next, a similar approach was used for the analysis of the proteome of Lactobacillus cells. Here, liquid MALDI MS/MS returned a lower overall number of identifications (84 proteins) as compared to the 188 proteins identified using solid MALDI MS/MS (Table 4). The relatively low number of protein identifications can be due to the composition of the Lactobacillus database, which has a lower number of residues per entry ( 300) compared to other (wellcurated) databases and has an extremely low number of only 41 entries with proteomic or transcriptomic evidence (http://hamap.expasy.org/proteomes/LACPL.html; accessed on $17^{\text {th }}$ June 2016). The above finding led to an investigation into the quality of the PSD spectra using liquid MALDI. Notably, the PSD MS/MS spectra revealed a strong unresolved peak near the theoretical $\mathrm{m} / \mathrm{z}$ values of the $\mathrm{b}_{\mathrm{n}-1} / \mathrm{y}_{\mathrm{n}-1}$ peptide fragment ions, as shown in Figure 4. In around half of the cases these peaks were closer to the theoretical $y_{n-1} m / z$ value while for the other half they were closer to the $b_{n-1}$ or $b_{n-1}+H_{2} O$ values. However, unresolved peaks were not present in all 
peptide spectra. A total of $42 \%$ of the BSA spectra had these unresolved peaks while the rest did not. The intensities of those peaks also varied with each peptide. For Lactobacillus proteins, there were unresolved peaks in $25 \%$ of the total MS/MS measurements using liquid MALDI, of which $10 \%$ (i.e. $2.5 \%$ of the total MS/MS measurements) could be matched by Mascot.

Further experiments were carried out to investigate the cause of the unresolved peaks, what they were and how to prevent them from having an adverse effect on the MS/MS analysis. One early indication was that the unresolved peaks are somehow related to the presence of AP in the liquid matrix. As mentioned earlier, the ammonium salt suppresses alkali-ion adduct formation for peptides and plays a similarly important role in the protonation and deprotonation of oligonucleotides ${ }^{21,24,29}$ and phosphopeptides. ${ }^{25}$

An experiment to test this hypothesis was conducted using the peptide angiotensin I from the peptide calibration standard II. AP was either used, omitted from the liquid MALDI preparation or replaced with ammonium citrate (AC). The resulting PSD spectra are shown in Figure 5. Without any ammonium salts (Figure 5(c)) the spectra did not show a large number of unresolved peaks but a few intense PSD ion signals were observed at around m/z 1080 which do not correlate to angiotensin I fragments. With AC (Figure 5(b)), unresolved peaks were observed similar to those seen when AP was used (Figure 5(a)) but these peaks were at lower as well as higher $\mathrm{m} / \mathrm{z}$ values. In contrast, the analogous experiment using the solid MALDI matrix showed no unresolved peaks in the spectrum (Figure 5(d)). Some of these spectral changes could be due to different chemistries provided by these additives or simply due to physical property changes of the liquid MALDI sample as a result of a change in surface tension or accumulation of ions on the surface. Unfortunately, no conclusive correlation to the appearance of these unwanted spectral features could be found. However, without ammonium salts in the 
liquid matrix the protein identification was adversely affected due to the increased presence of salt adducts and matrix clusters in the MS spectrum. Thus, the use of AP is still desirable in liquid MALDI.

Interestingly, in the presence of ammonium salt, the laser energy threshold value needed for the generation of MALDI analyte ions was higher than without ammonium salt: $\mathrm{E}_{\text {ions }}(\mathrm{AP})>$ $E_{\text {ions }}(A C)>E_{\text {ions }}$ (no ammonium salt). An explanation for this can possibly be found in the negligible UV absorption for ammonium salts and a potential accumulation of their ionic constituents preferentially on the surface of the liquid MALDI droplet, thus significantly lowering the absorbance of the irradiated sample volume and demanding higher laser energy for successful MALDI ion generation. Previous reports suggest that ammonium cations as monovalent and polarizable ions show a high propensity to be near (aqueous) droplet surfaces, supporting the possibility of an absorbance dilution effect. ${ }^{30,31}$ In particular, recent data show that water droplets doped with specific ionic compounds can even produce thin films on the droplets' surface with a thickness of approximately $1 \mu \mathrm{m}{ }^{32}$, which is greater than the ablation depth in liquid UV-MALDI (and the penetration depth of the laser light), indicating that the absorbance can be significantly reduced by the creation of such thin films if they consist of lowabsorbing compounds. Higher laser energy requirements generally result in higher internal energies of the analyte ions and therefore greater unimolecular (metastable) decay.

However, beside the sample preparation, instrumental and fragmentation parameters can also affect the amount and type of detected fragment ions. To investigate this, the standard peptide angiotensin I was examined using CID on a hybrid Q-TOF mass spectrometer. Spectra were acquired from 100 fmol on target using both solid and liquid MALDI. Fragment ion lists obtained from the MS/MS spectra were compared with the theoretical fragment ion masses of 
angiotensin I calculated using Protein Prospector (http://prospector.ucsf.edu) at a fragment ion mass tolerance of less than \pm 0.2 Da. The CID spectra of angiotensin I acquired with liquid MALDI gave greater peptide sequence information and higher intensities of fragment ion signals (which were also of equivalent quality) compared to the spectra obtained by solid MALDI on the same instrument (Figure 6(a,b)). The LSM MS/MS spectra, however, showed a high level of background noise (Figure 6(b)), whose ions do not match any theoretical CID fragment ions and could originate from chemical background noise from the matrix as more laser power was required with the liquid than solid sample. It is interesting to note that no unresolved intense peaks were observed in the liquid MALDI CID spectra using the Q-TOF instrument (Figure 6(b)). Unresolved intense fragment ion peaks appeared only in PSD spectra acquired on the Ultraflex axial TOF instrument (Figure 6(d)). In the Ultraflex instrument, ions normally fragment before entering the LIFT cell where they then gain kinetic energy from the LIFT acceleration, resulting in kinetic energies in the range of $19-27 \mathrm{keV}$. In the presence of an ammonium salt, fragmentation could be delayed and occur late when the ions are in the LIFT cell or after they have left it. Here, the fragment ions may have a kinetic energy below $19 \mathrm{keV}$. However, if the ions were to fragment late, they would acquire lower kinetic energies and travel much slower through the (reflector) TOF resulting in a shift to an apparently higher mass and with poorer resolution.

\section{Conclusions}

This study investigated the use of liquid MALDI with an automated nanoHPLC MALDI MS(/MS) set-up. The set-up was successfully used for the analysis of trypsin digests of BSA and Lactobacillus proteins. For the analysis of a BSA digest, the liquid MALDI sample preparation

yielded PMFs with a higher sequence coverage and a higher Mascot score than the equivalent 
solid MALDI sample preparation, while the relative performances in MS/MS ion searches were similar. For the Lactobacillus proteome, liquid MALDI samples can identify highly abundant proteins. However, when using liquid MALDI, PSD spectra show intense unresolved peaks around the $\mathrm{y}_{\mathrm{n}-1} / \mathrm{b}_{\mathrm{n}-1}$ fragment ions, particularly in the presence of ammonium salts. These peaks were not seen when spectra were acquired on a Q-TOF instrument using CID. Thus, future work will center on the optimization of the analysis of complex proteomic samples using liquid MALDI and automated LC-MALDI MS/MS on a Q-TOF instrument, and further investigate the origin of the intense unresolved PSD fragment ion signals observable with liquid MALDI.

\section{Acknowledgements}

This research was supported by the Royal Thai Government. We would like to acknowledge the Chemical Analysis Facility at the University of Reading for access to the Ultraflex TOF/TOF instrument.

\section{Conflict of Interest Disclosure}

The authors declare no competing financial interest. 


\section{References}

1 R. Cramer, K. Dreisewerd. in The Encyclopedia of Mass Spectrometry (Eds.: M. L. Gross, R. M. Caprioli), Elsevier, Amsterdam, The Netherlands 2007, pp. 646.

2 D. E. Hoffmann, V. Stroobant. Mass Spectrometry: principles and applications, 3rd ed., John Wiley \& Sons, Inc, Chichester, England, 2007.

3 D. S. Nagra, L. Li. Liquid chromatography-time-of-flight mass spectrometry with continuous-flow matrix-assisted laser desorption ionization. J Chromatogr $A$ 1995, 711, 235.

4 E. T. P. Sze, T. W. D. Chan, G. Wang. Formulation of Matrix Solutions for Use in Matrix-Assisted Laser Desorption/lonization of Biomolecules. J Am Soc Mass Spectrom 1998, 9, 166.

5 M. Towers, R. Cramer. Liquid Matrices for Analyses by UV-MALDI Mass Spectrometry. Spectroscopy 2007, 22, 24.

6 R. Cramer, S. Corless. Liquid ultraviolet matrix-assisted laser desorption/ionization-mass spectrometry for automated proteomic analysis. Proteomics 2005, 5, 360.

$7 \quad$ M. Palmblad, R. Cramer. Liquid Matrix Deposition on Conductive Hydrophobic Surfaces for Tuning and Quantitation in UV-MALDI Mass Spectrometry. J Am Soc Mass Spectrom 2007, 18, 693.

8 Y. Fukuyama, K. Takeyama, S. Kawabata, S. Iwamoto, K. Tanaka. An optimized matrix-assisted laser desorption/ionization sample preparation using a liquid matrix, 3-aminoquinoline/alpha-cyano-4-hydroxycinnamic acid, for phosphopeptides. Rapid Commun Mass Spectrom 2012, 26, 2454.

9 K. Kaneshiro, Y. Fukuyama, S. Iwamoto, S. Sekiya, K. Tanaka. Highly Sensitive MALDI Analyses of Glycans by a New Aminoquinoline-Labeling Method Using 3Aminoquinoline/a-Cyano-4-hydroxycinnamic Acid Liquid Matrix. Anal Chem 2011, 83, 3663.

10 S. Sekiya, K. Taniguchi, K. Tanaka. On-target separation of analyte with 3aminoquinoline/a-cyano-4-hydroxycinnamic acid liquid matrix for matrix-assisted laser desorption/ionization mass spectrometry. Rapid Commun Mass Spectrom 2012, 26, 693.

11 T. Shuo, N. Koshikawa, D. Hoshino, T. Minegishi, H. Ao-Kondo, M. Oyama, S. Sekiya, S. Iwamoto, K. Tanaka, M. Seiki. Detection of the Heterogeneous OGlycosylation Profile of MT1-MMP Expressed in Cancer Cells by a Simple MALDI-MS Method. PLoS ONE 2012, 7, e43751. 
12 V. S. K. Kolli, R. Orlando. A new matrix for matrix-assisted laser desorption/ionization on magnetic sector instruments with point detectors. Rapid Commun Mass Spectrom 1996, 10, 923.

13 E. Mirgorodskaya, C. Braeuer, P. Fucini, H. Lehrach, J. Gobom. Nanoflow liquid chromatography coupled to matrix-assisted laser desorption/ionization mass spectrometry: sample preparation, data analysis, and application to the analysis of complex peptide mixtures. Proteomics 2005, 5, 399.

14 F. Pereira, X. Niu, A. J. deMello. A Nano LC-MALDI Mass Spectrometry Droplet Interface for the Analysis of Complex Protein Samples. PLOS ONE 2013, 8, e63087.

15 S. Weidmann, S. Kemmerling, S. Mädler, H. Stahlberg, T. Braun, R. Zenobi. lonic liquids as matrices in microfluidic sample deposition for high-mass matrixassisted laser desorption/ionization mass spectrometry. Eur J Mass Spectrom 2012, 18, 279.

16 W. M. Bodnar, R. K. Blackburn, J. M. Krise, M. A. Moseley. Exploiting the complementary nature of LC/MALDI/MS/MS and LC/ESI/MS/MS for increased proteome coverage. J Am Soc Mass Spectrom 2003, 14, 971.

17 Y. Yang, S. Zhang, K. Howe, D. B. Wilson, F. Moser, D. Irwin, T. W. Thannhauser. A Comparison of nLC-ESI-MS/MS and nLC-MALDI-MS/MS for GeLC-Based Protein Identification and ITRAQ-Based Shotgun Quantitative Proteomics. J Biomol Tech 2007, 18, 226.

18 S. J. Hattan, J. Marchese, N. Khainovski, S. Martin, P. Juhasz. Comparative Study of [Three] LC-MALDI Workflows for the Analysis of Complex Proteomic Samples. J Proteome Res 2005, 4, 1931.

19 R. Cramer, A. Pirkl, F. Hillenkamp, K. Dreisewerd. Liquid AP-UV-MALDI Enables Stable Ion Yields of Multiply Charged Peptide and Protein lons for Sensitive Analysis by Mass Spectrometry. Angew Chem Int Ed 2013, 52, 2364.

20 R. Cramer, J. Gobom, E. Nordhoff. High-throughput proteomics using matrixassisted laser desorption/ ionization mass spectrometry. Expert Rev Proteomics 2005, 2, 407.

21 Y. F. Zhu, N. I. Taranenko, S. L. Allman, S. A. Martin, L. Haff, C. H. Chen. The Effect of Ammonium Salt and Matrix in the Detection of DNA by Matrix-assisted Laser Desorption/lonization Time-of-flight Mass Spectrometry. Rapid Commun Mass Spectrom 1996, 10, 1591.

22 I. P. Smirnov, X. Zhu, T. Taylor, Y. Huang, P. Ross, I. A. Papayanopoulos, S. A. Martin, D. J. Pappin. Suppression of $\alpha$-Cyano-4-hydroxycinnamic Acid Matrix Clusters and Reduction of Chemical Noise in MALDI-TOF Mass Spectrometry. Anal Chem 2004, 76, 2958. 
23 X. Zhu, I. A. Papayannopoulos. Improvement in the Detection of Low Concentration Protein Digests on a MALDI TOF/TOF Workstation by Reducing $\alpha$ Cyano-4-hydroxycinnamic Acid Adduct lons. J Biomol Tech 2003, 14, 298.

24 G. J. Currie, J. R. Yates. Analysis of oligodeoxynucleotides by negative-ion matrix-assisted laser desorption mass spectrometry. J Am Soc Mass Spectrom 1993, 4, 955.

25 J. M. Asara, J. Allison. Enhanced detection of phosphopeptides in matrixassisted laser desorption/ionization mass spectrometry using ammonium salts. $J$ Am Soc Mass Spectrom 1999, 10, 35.

26 Y. C. L. Li, S.-w. Cheng, T. W. D. Chan. Evaluation of ammonium salts as comatrices for matrix-assisted laser desorption/ionization mass spectrometry of oligonucleotides. Rapid Commun Mass Spectrom 1998, 12, 993.

27 M. Zabet-Moghaddam, E. Heinzle, M. Lasaosa, A. Tholey. Pyridinium-based ionic liquid matrices can improve the identification of proteins by peptide massfingerprint analysis with matrix-assisted laser desorption/ionization mass spectrometry. Anal Bioanal Chem 2006, 384, 215.

28 C. D. Calvano, S. Carulli, F. Palmisano. Aniline/alpha-cyano-4-hydroxycinnamic acid is a highly versatile ionic liquid for matrix-assisted laser desorption/ionization mass spectrometry. Rapid Commun Mass Spectrom 2009, 23, 1659.

29 U. Pieles, W. Zürcher, M. Schär, H. E. Moser. Matrix-assisted laser desorption ionization time-of-flight mass spectrometry: a powerful tool for the mass and sequence analysis of natural and modified oligonucleotides. Nucleic Acids Res 1993, 21, 3191.

30 S. Gopalakrishnan, P. Jungwirth, D. J. Tobias, H. C. Allen. Air-Liquid Interfaces of Aqueous Solutions Containing Ammonium and Sulfate: Spectroscopic and Molecular Dynamics Studies. J Phys Chem B 2005, 109, 8861.

31 C. Tian, S. J. Byrnes, H.-L. Han, Y. R. Shen. Surface Propensities of Atmospherically Relevant lons in Salt Solutions Revealed by Phase-Sensitive Sum Frequency Vibrational Spectroscopy. J Phys Chem Lett 2011, 2, 1946.

32 X. Zeng, Y. Zhang, Z. Xia, L. Wang, C. Wang, Y. Huang, R. Shen, W. Wen. Surface evolution of manganese chloride aqueous droplets resulting in selfsuppressed evaporation. Sci Rep 2015, 5. 


\section{Tables}

Table 1. Comparison of peptide mass fingerprints of a BSA digest using solid and liquid MALDI sample preparations ( $n=3$, searching the Swiss-Prot database).

\begin{tabular}{cccccc}
\hline & $\begin{array}{c}\text { Picked } \\
\text { peaks* }\end{array}$ & $\begin{array}{c}\text { Matched } \\
\text { peaks }\end{array}$ & $\begin{array}{c}\text { Sequence } \\
\text { coverage } \\
(\%)\end{array}$ & $\begin{array}{c}\text { Intensity } \\
\text { coverage } * * * \\
(\%)\end{array}$ & $\begin{array}{c}\text { Mascot } \\
\text { score*** }\end{array}$ \\
\hline $\begin{array}{c}\text { Liquid } \\
\text { MALDI }\end{array}$ & $153 \pm 66$ & $46 \pm 9$ & $65 \pm 3$ & $52 \pm 7$ & $258 \pm 11$ \\
$\begin{array}{c}\text { Solid } \\
\text { MALDI }\end{array}$ & $172 \pm 74$ & $44 \pm 5$ & $60 \pm 1$ & $42 \pm 5$ & $207 \pm 20$ \\
\hline
\end{tabular}

* Peaks were picked above $\mathrm{m} / \mathrm{z} 800$ with a signal-to-noise ratio of $\geq 6$.

** This parameter is calculated by Biotools and represents the sum of the intensities of the matched peaks divided by the sum of the intensities of the peaks selected (multiplied by 100).

*** Mascot scores greater than 61 are significant. 
Table 2. Comparison of MS/MS ion searches of a BSA digest using solid and liquid MALDI sample preparations $(n=3$, searching the Swiss-Prot database; peaks were selected if the signalto-noise ratio was $\geq 3$ ).

\begin{tabular}{ccccc}
\hline & $\begin{array}{c}\text { Number of } \\
\text { acquired MS/MS } \\
\text { spectra }\end{array}$ & $\begin{array}{c}\text { Matched } \\
\text { peptides }\end{array}$ & $\begin{array}{c}\text { Protein } \\
\text { sequence } \\
\text { coverage (\%) }\end{array}$ & $\begin{array}{c}\text { Mascot } \\
\text { score }\end{array}$ \\
\hline $\begin{array}{c}\text { Liquid } \\
\text { MALDI }\end{array}$ & $180 \pm 49$ & $25 \pm 5$ & $50 \pm 8$ & $965 \pm 320$ \\
$\begin{array}{c}\text { Solid } \\
\text { MALDI }\end{array}$ & $255 \pm 73$ & $25 \pm 5$ & $47 \pm 9$ & $1299 \pm 244$ \\
\hline
\end{tabular}


Table 3. List of BSA peptide ions found in more than one of three replicates for solid and liquid MALDI sample preparations.

\begin{tabular}{|c|c|c|c|}
\hline $\begin{array}{l}\text { Peptide } \\
\text { ions }(\mathrm{m} / \mathrm{z})\end{array}$ & Peptide sequence & $\begin{array}{c}\text { Occurrences } \\
\text { in solid } \\
\text { MALDI }\end{array}$ & $\begin{array}{c}\text { Occurrences } \\
\text { in liquid } \\
\text { MALDI }\end{array}$ \\
\hline 922.53 & IETMREK & & $\mathrm{X}$ \\
\hline 927.52 & YLYEIAR & $\bar{X}$ & $\mathrm{X}$ \\
\hline 1014.62 & QTALVELLK & & $\mathrm{X}$ \\
\hline 1107.48 & EAC(Carbamidomethyl)FAVEGPK & & $\mathrm{X}$ \\
\hline 1138.51 & $\mathrm{C}($ Carbamidomethyl)C(Carbamidomethyl)TESLVNR & & $\mathrm{X}$ \\
\hline 1142.81 & KQTALVELLK & $\bar{X}$ & $\bar{X}$ \\
\hline 1163.69 & LVNELTEFAK & $\mathrm{X}$ & $\mathrm{X}$ \\
\hline 1249.65 & FKDLGEEHFK & $\mathrm{X}$ & $\mathrm{X}$ \\
\hline 1283.60 & HPEYAVSVLLR & $\mathrm{X}$ & $\mathrm{X}$ \\
\hline 1305.72 & HLVDEPQNLIK & $\mathrm{X}$ & $\mathrm{X}$ \\
\hline 1399.69 & TVMENFVAFVDK & $\mathrm{X}$ & $\mathrm{X}$ \\
\hline 1415.70 & TVM(Oxidation)ENFVAFVDK & $\bar{X}$ & \\
\hline 1419.76 & SLHTLFGDELC(Carbamidomethyl)K & $\bar{X}$ & $\bar{X}$ \\
\hline 1439.87 & RHPEYAVSVLLR & $\mathrm{X}$ & $\mathrm{X}$ \\
\hline 1443.65 & YIC(Carbamidomethyl)DNQDTISSK & & $\mathrm{X}$ \\
\hline 1478.50 & ETYGDMADC(Carbamidomethyl)C(Carbamidomethyl)EK & & $\mathrm{X}$ \\
\hline 1479.76 & LGEYGFQNALIVR & $\bar{X}$ & $\bar{X}$ \\
\hline 1502.64 & EYEATLEEC(Carbamidomethyl)C(Carbamidomethyl)AK & & $\mathrm{X}$ \\
\hline 1511.74 & VPQVSTPTLVEVSR & $\bar{X}$ & $\bar{X}$ \\
\hline 1532.80 & LKEC(Carbamidomethyl)C(Carbamidomethyl)DKPLLEK & $\mathrm{X}$ & $\mathrm{X}$ \\
\hline 1554.68 & DDPHAC(Carbamidomethyl)YSTVFDK & $\mathrm{X}$ & $\mathrm{X}$ \\
\hline 1567.81 & DAFLGSFLYEYSR & $\mathrm{X}$ & $\mathrm{X}$ \\
\hline 1576.72 & LKPDPNTLC(Carbamidomethyl)DEFK & & $\bar{X}$ \\
\hline 1639.89 & KVPQVSTPTLVEVSR & $\bar{X}$ & $\bar{X}$ \\
\hline 1673.79 & QEPERNEC(Carbamidomethyl)FLSHK & $\mathrm{X}$ & $\mathrm{X}$ \\
\hline 1724.84 & MPC(Carbamidomethyl)TEDYLSLILNR & $\underline{X}$ & $\mathrm{X}$ \\
\hline 1740.81 & $\mathrm{M}$ (Oxidation)PC(Carbamidomethyl)TEDYLSLILNR & $\mathrm{X}$ & \\
\hline 1747.60 & YNGVFQEC(Carbamidomethyl)C(Carbamidomethyl)QAEDK & $\bar{X}$ & $\bar{X}$ \\
\hline 1749.66 & $\begin{array}{c}\text { EC(Carbamidomethyl)C(Carbamidomethyl)HGDLLEC } \\
\text { (Carbamidomethyl)ADDR }\end{array}$ & $\mathrm{X}$ & $\mathrm{X}$ \\
\hline 1880.71 & RPC(Carbamidomethyl)FSALTPDETYVPK & $\mathrm{X}$ & $\mathrm{X}$ \\
\hline 1888.86 & HPYFYAPELLYYANK & $\bar{X}$ & \\
\hline 1907.88 & LFTFHADIC(Carbamidomethyl)TLPDTEK & $\mathrm{X}$ & \\
\hline 2458.30 & DAIPENLPPLTADFAEDKDVC(Carbamidomethyl)K & $\mathrm{X}$ & \\
\hline
\end{tabular}


Table 4. Comparison of MS/MS ion searches for the L. plantarum proteome analysis using solid and liquid MALDI sample preparations ( $n=3$, searching the in house lactobacillus database).

\begin{tabular}{cccc}
\hline & $\begin{array}{c}\text { No. of acquired } \\
\text { MS/MS spectra }\end{array}$ & $\begin{array}{c}\text { No. of matching } \\
\text { peptides }\end{array}$ & $\begin{array}{c}\text { No. of identified } \\
\text { proteins }\end{array}$ \\
\hline $\begin{array}{c}\text { Liquid } \\
\text { MALDI }\end{array}$ & $2,599 \pm 1,219$ & $319 \pm 8$ & $84 \pm 4$ \\
\hline $\begin{array}{c}\text { Solid } \\
\text { MALDI }\end{array}$ & $2,785 \pm 1,219$ & $888 \pm 139$ & $188 \pm 21$ \\
\hline
\end{tabular}




\section{Figure Captions}

Figure 1. Images of a solid (A) and liquid (B) MALDI sample of a BSA digest. Both samples were robotically deposited on an AnchorChip target.

Figure 2. MALDI-PSD-TOF/TOF MS/MS spectra of the tryptic BSA peptide at m/z 1907.9 using solid (a) and liquid (b) MALDI sample preparation. (c) Mass list of the fragment ions with their mass accuracy for both sample preparations.

Figure 3. MALDI-PSD-TOF/TOF MS/MS spectra of the tryptic BSA peptide at m/z 927.4 using liquid (a) and solid (b) MALDI sample preparation.

Figure 4. Liquid MALDI-PSD-TOF/TOF MS/MS spectra of a tryptic BSA peptide at $\mathrm{m} / \mathrm{z}$ 1107.5 with a successful database match (a) and m/z 1034.6 with an unsuccessful database match (b). Both spectra show a strong unresolved peak (see also inset).

Figure 5. MALDI-PSD-TOF/TOF MS/MS spectra of angiotensin I (DRVYIHPFHL) using liquid MALDI sample preparations with (a) $10 \mathrm{mM}$ AP (b) $10 \mathrm{mM} \mathrm{AC}$ and (c) without AP or AC, and (d) using CHCA-based solid MALDI sample preparation. Asterisks (*) mark ion signals matching angiotensin I fragment ions.

Figure 6. Fragment ion mass spectra of $100 \mathrm{fmol}$ angiotensin I. Q-TOF-CID MS/MS spectra using solid (a) and liquid (b) MALDI. Axial TOF-PSD MS/MS spectra using solid (c) and liquid (d) MALDI. Spectra are annotated according to the theoretical angiotensin I fragment ion pattern. 
Figure 1

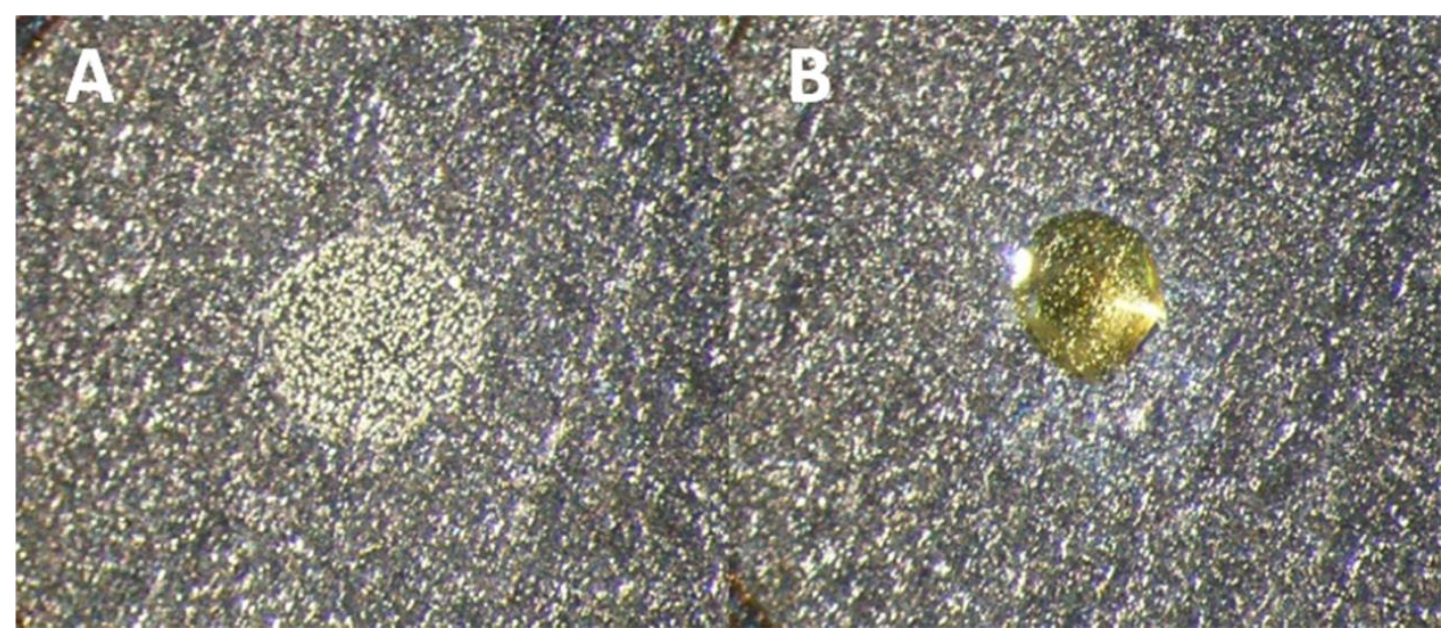


Figure 2

(a)

(b)
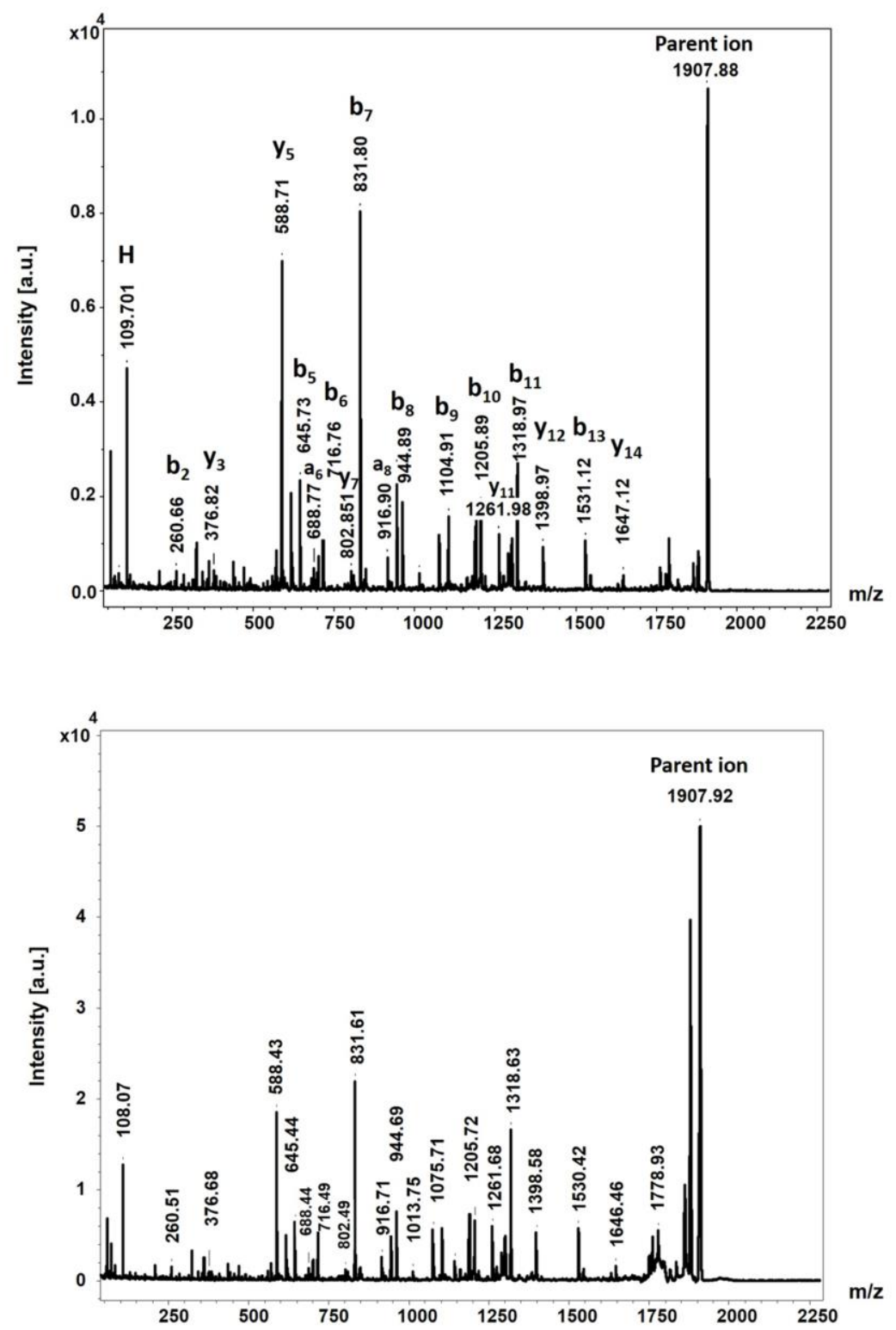

(c)

\begin{tabular}{|c|c|c|c|c|c|c|c|c|c|c|c|c|c|c|c|c|c|}
\hline & \multicolumn{17}{|c|}{ Fragment error $(\Delta \mathrm{mmu})$} \\
\hline & $b_{2}$ & $y_{3}$ & y5 & $b_{5}$ & a6 & $b_{6}$ & $y 7$ & $b_{7}$ & a8 & b8 & b9 & $b_{10}$ & $\mathrm{y}_{11}$ & $b_{11}$ & $y_{12}$ & $b_{13}$ & $y_{14}$ \\
\hline $\begin{array}{c}\text { Theoretical } \\
\mathrm{m} / \mathrm{z}\end{array}$ & 261.16 & 377.20 & 589.28 & 646.33 & 689.38 & 717.37 & 803.41 & 832.39 & 917.49 & 945.48 & 1105.51 & 1206.56 & 1262.59 & 1319.65 & 1399.65 & 1531.73 & 647.77 \\
\hline $\begin{array}{l}\text { Solid } \\
\text { MALDI }\end{array}$ & +1913.8 & +1012.9 & +965.2 & +929.6 & +867.5 & +852.9 & +701.4 & +713.4 & +631.1 & +617.6 & +545.9 & +550.5 & +479.4 & +505.7 & +485.9 & +393.7 & +390.4 \\
\hline $\begin{array}{l}\text { Liquid } \\
\text { MALDI }\end{array}$ & +2484.3 & +1376.2 & +1437.0 & +1381.3 & +1356.3 & +1219.6 & +1145.7 & +939.2 & +840.3 & +834.4 & +842.6 & +693.0 & +716.2 & +764.0 & +761.8 & +848.1 & +793.4 \\
\hline
\end{tabular}


Figure 3

(a)

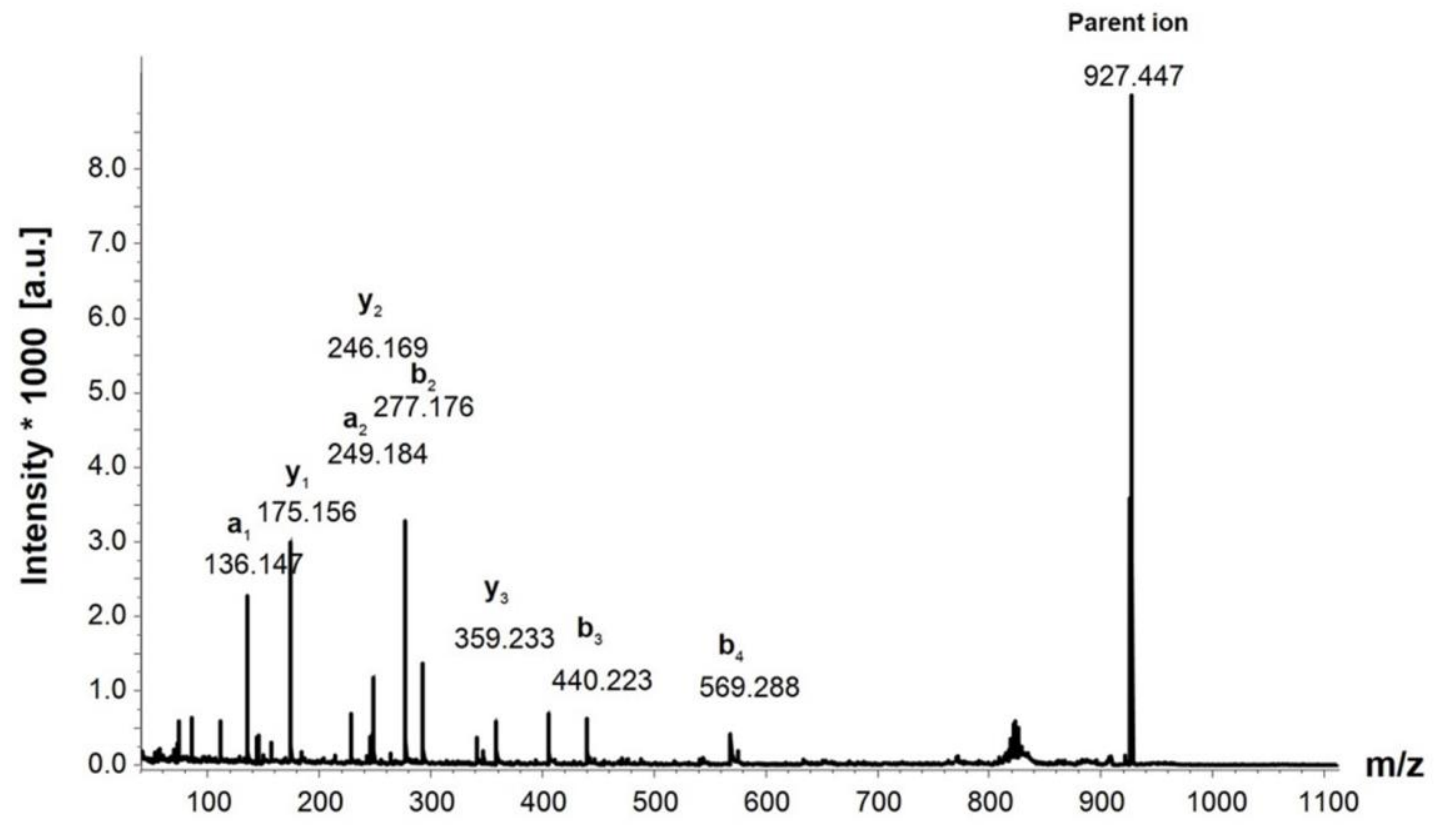

(b)

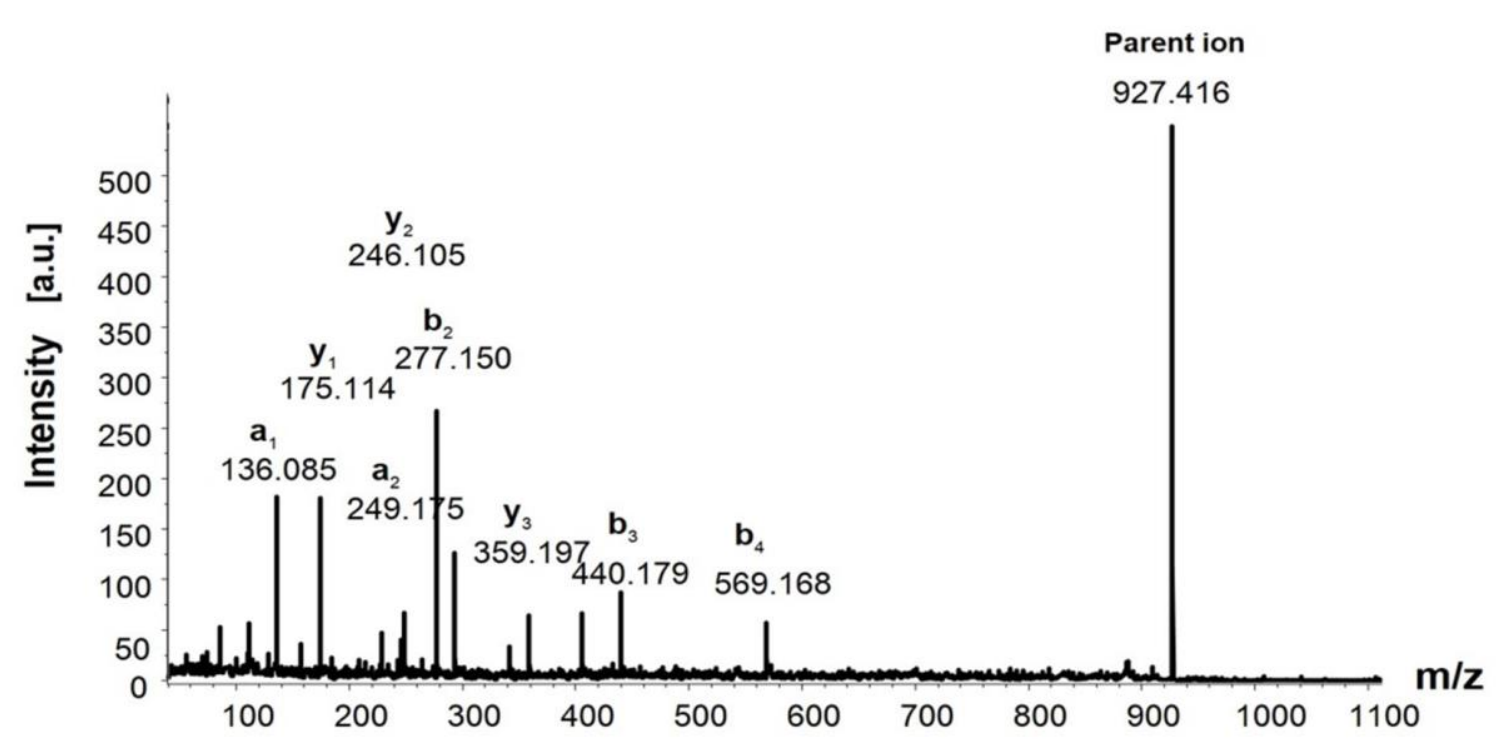


Figure 4

(a)

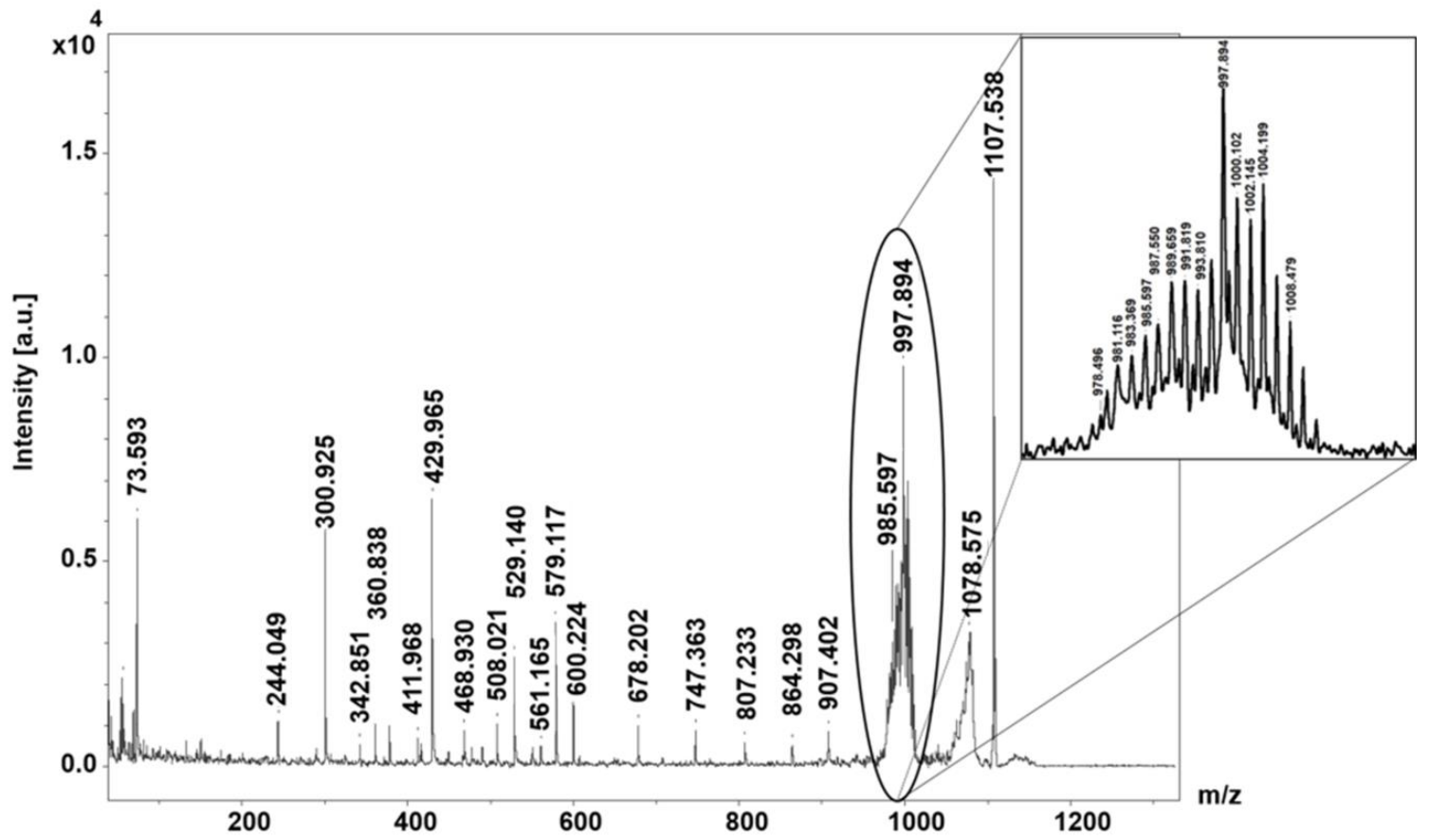

(b)

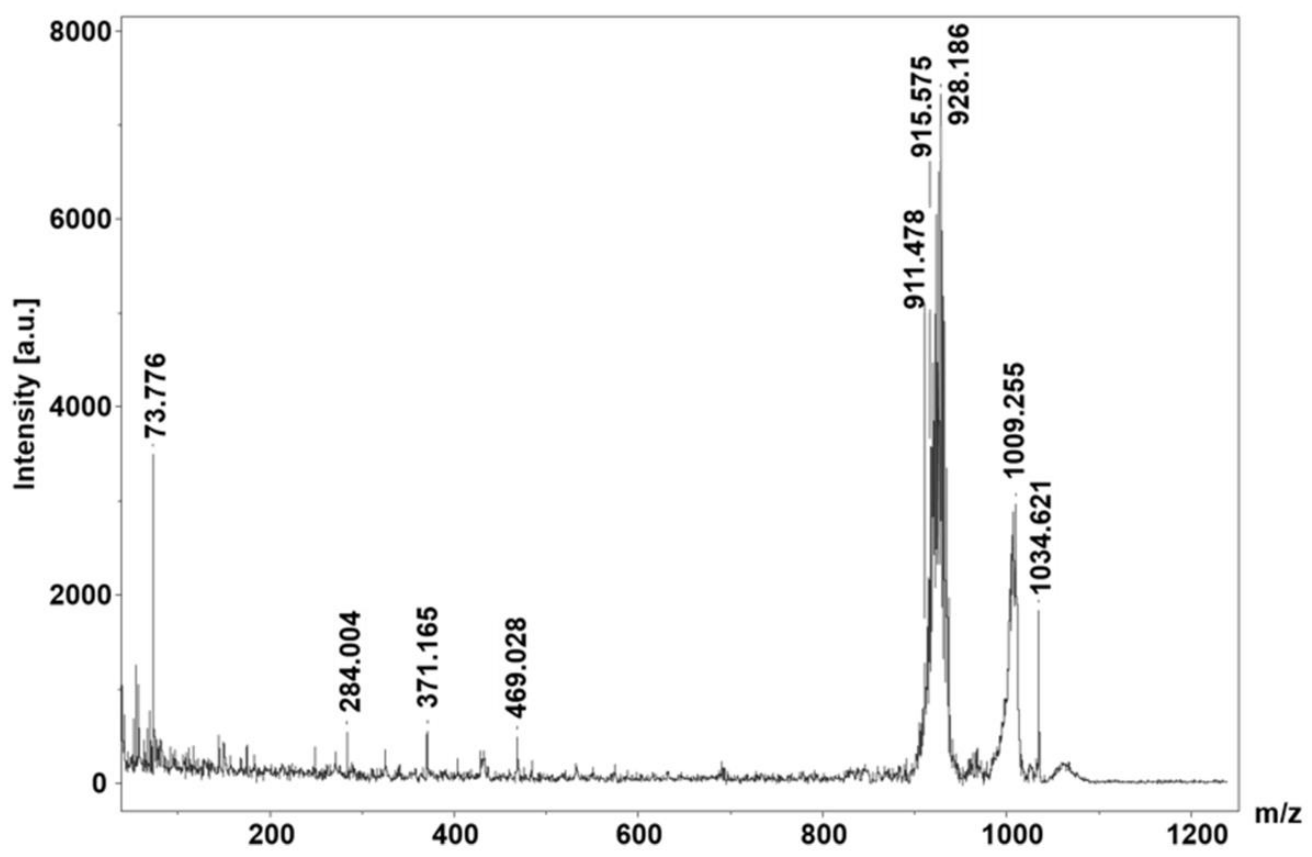


Figure 5

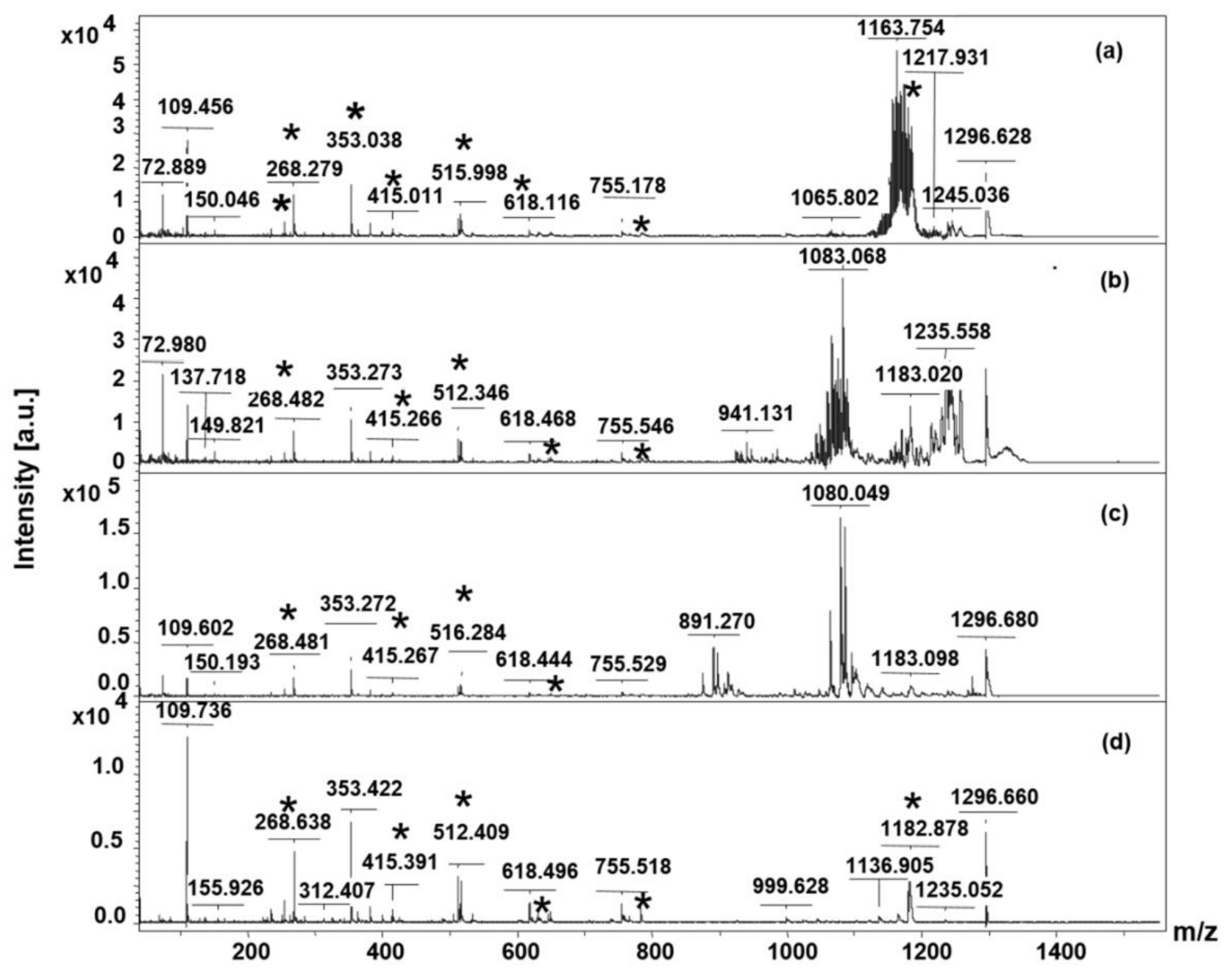


Figure 6

(a)

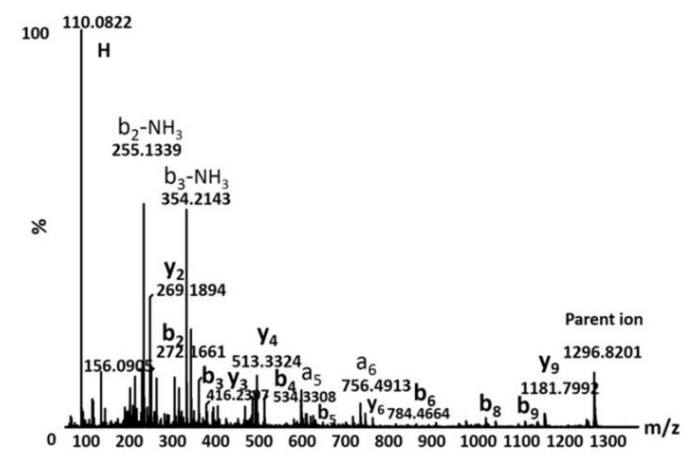

(b)

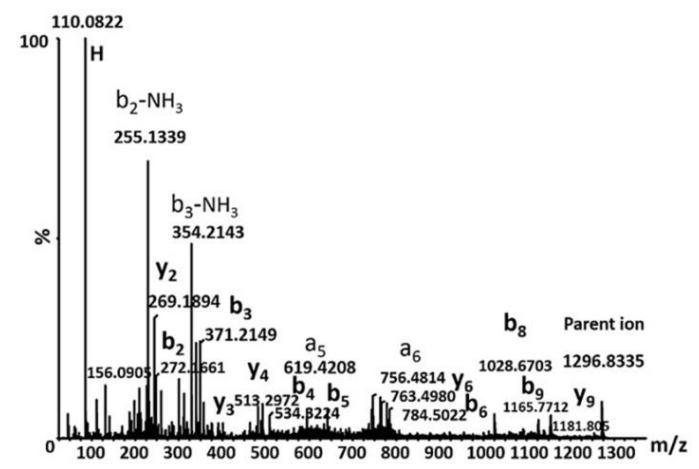

(c)

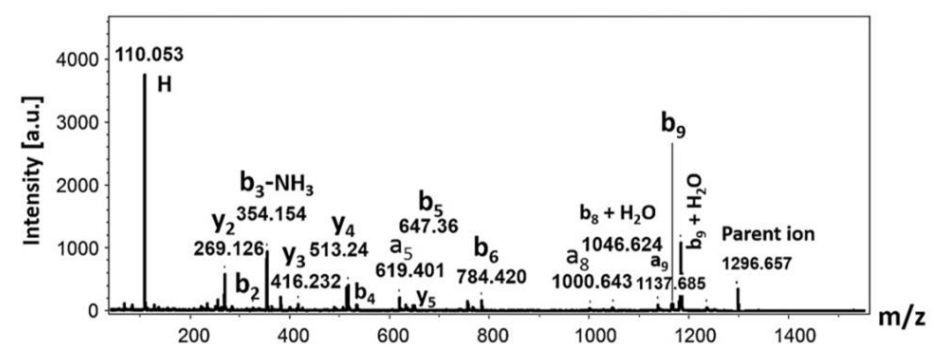

(d)

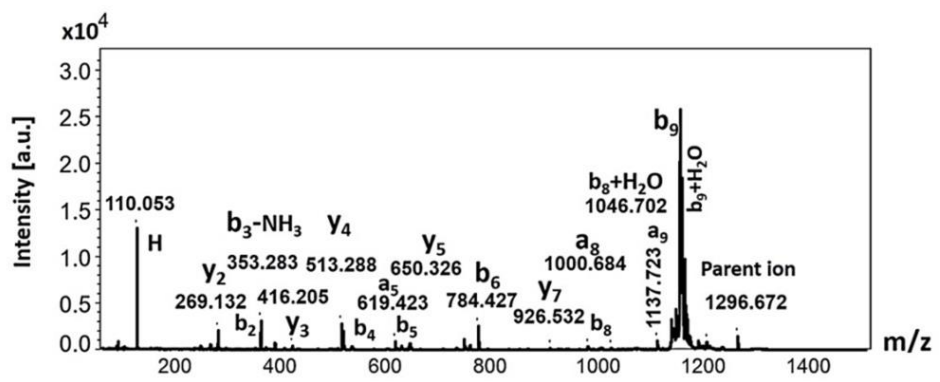




\section{For TOC only}

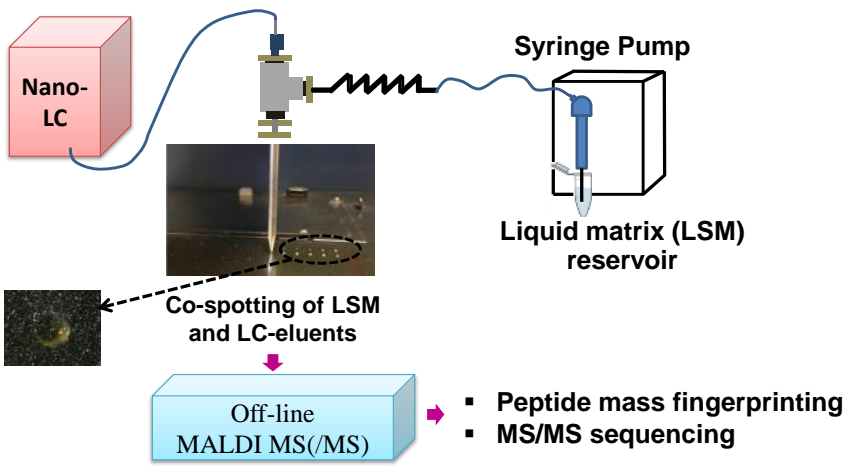

